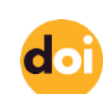

http://doi.org/10.22282/ojrs.2021.87

\title{
Examining the Effects of Core Training Applied on Sport Climbers from Primary Schools
}

\author{
Çağatay DERECELI
}

ABSTRACT

\begin{abstract}
The most important characteristic of core training is to contain such body motions with one's own body weight. That process does not have any obstacle for growing children.

The aim of this study is to determine the flexibility and force parameters of sport climbers from among second-grade primary school students who exercise for six weeks with a core training program. From this point of view, it will be possible to use this training model for children in many sports branches. After the participants were preconditions for the trainings included in the study, the sample's $(n=42)$ first measurements were obtained on 7 October 2020. The participants warmed up dynamically for $10 \mathrm{~min}$ before the
\end{abstract}

measurements in order to prevent injuries. While the control group $(\mathrm{CG}=22)$ continued their routine training program, the exercise group $(\mathrm{EG}=20)$ had a core training program. The comparison of the last measurements after the six-week training program showed considerable differences in the flexibility and force parameters. Owing to these results, this training method was significantly effective, and it could be applied among children taking part in different branches of sports.

Key Words: Core training, Flexibility, Schools' Sport, Sport Climbing, Strength 


\section{INTRODUCTION}

Core training is an exercise program including movements based only on one's own body weight for strengthening lumbo-pelvic-hip muscles which provide core stabilization [6, 2]. The lumbopelvic-hip complex has been referred to as the core, and it connects the upper and lower extremities [26]. The core area described to include 29 different body portions contains the human body's center of gravity with lumbopelvic, hip and abdomen muscles [20]. Core exercises are useful for muscle balance and strength and effective on performing the right movements for these muscles. Strengthening core area muscles is not for only performance, but it is also beneficial for the individual's posture [24]. Core training is mostly used for improving balance, strength, anatomical functioning and flexibility [19]. It is thought that core training is important for sport climbing which coordinates strength, balance and flexibility. Recent studies have provided information only on core training about strength and balance improvement in general $[7,19,5,10,1,13,21,11,18,12,9]$.

\section{MATERIALS AND METHODS}

\section{Participants}

The study was started and had been mostly completed before the COVID-19 pandemic period. Its incomplete portion was caused by the fact that all competitions were cancelled after the announcement of the global pandemic. Data on the competition outcomes of the participants could not be collected and integrated into the study protocol. The participants were residing in the Kartal district of the province of Istanbul in Turkey. All measurements and interventions were made with the participation of physical education teachers.

All volunteering athletes were allowed to participate in the study. In addition to this, the participants were also informed that those who missed at least two sessions would be excluded from the study. At the end of the study, 20 participants in total completed the entire training program.

\section{Design}

The first measurements were obtained on 7 October 2020 subsequent to preconditioning the participants $(n=42)$. For avoiding injuries, the participants had $10 \mathrm{~min}$ of dynamic warm up 
before their measurements were taken. The training program was created in the form of $10 \mathrm{~min}$ of dynamic warm up, core training for $60 \mathrm{~min}$ and cooling exercise for $80 \mathrm{~min}$. No flexibility training was performed by the participants within the entire study. The core training movements included 1 set $\times 12$ repetitions for the first two weeks and 2 sets $\times 12$ repetitions for the last four weeks. Exercises that required effective climbing abilities were specially selected as they could enhance athletic performance.

\section{Instruments}

In order to measure flexibility and analyze the results on hamstring and torso flexion, a sit and rich table was utilized (Lafayette Instrument Company, Lafayette, IN). After 5 min of warm up, the participants started to exercise in the form of sitting down flat and leaning onto a panel followed by tilting their torso forward without bending their knees. Afterwards, they tried to push a slipping bar by hands with to the maximum extent. After waiting for a while, it was time to stretch forward and backward to the farthest points. The higher value was recorded out of two attempts. For measuring body extension (TEX), the participant faced a wall while contacting the wall with their pelvis and body. The distance between the sternal notch and the wall was measured and recorded. Next, the researcher supported the participant's pelvis and pushed their waist as backward as possible. In the last step, the distance between the sternal notch and the wall was measured again. The difference between the two values that were obtained was recorded in units of $\mathrm{cm}$. The measurements were repeated for three times, and the maximum value was recorded [16].

The measurement of the body lateral flexion (TLF) involved that participant standing narrowly opening their feet and keeping their arms next to their sides. Firstly, the point where the distal part of the 3rd phalanx and the femur contacted was marked. The participant performed lateral flexion, and then, the new point of the distal part of the 3rd phalanx was marked again. The distance between the two marks was measured and recorded in units of $\mathrm{cm}$. The measurements were repeated three times, and higher values were recorded [23].

The bent arm hang (BAH) test for endurance and the hand grip strength (HGS) test for grip were conducted as a part of the pretests and posttests to measure strength. The Bent Arm Hang test process involved the participant hanging on a bar with two arms, bending their arms and carrying their body upwards. The participant started in a stationary position on the bar, and 
the timing began. The participant's total duration of hanging on air was measured. Time was stopped when the participant let go. Takei's TKK 5401 model hand grip dynamometer was put to use to assess the strength of the participant's hand grip. This instrument reports the strength of the left and right forearm flexors in units of kgf. All measurements were made by the researcher.

Statistical Analysis. The data were analyzed using SPSS (Statistical Package for the Social Sciences). The normality of the measurement values was checked by Shapiro-Wilk test. According to the result of the test, the parametric independent-samples t-test was used for the intergroup comparisons, and paired-samples t-test was used for the intragroup comparisons. The level of statistical significance was taken as $\mathrm{p}<0.05$, and the confidence interval was accepted as $95 \%$.

\section{RESULTS}

Table 1. Descriptive Findings

\begin{tabular}{|c|c|c|c|c|}
\hline \multicolumn{2}{|c|}{ Descriptive findings } & $\mathrm{N}$ & $\%$ & Total \\
\hline \multirow{2}{*}{ Sex } & Female & 20 & 47.6 & \multirow{12}{*}{42} \\
\hline & Male & 22 & 52.4 & \\
\hline \multirow{4}{*}{$\begin{array}{l}\text { Level of } \\
\text { Education }\end{array}$} & 5 & 10 & 23.8 & \\
\hline & 6 & 10 & 23.8 & \\
\hline & 7 & 11 & 26.2 & \\
\hline & 8 & 11 & 26.2 & \\
\hline \multirow{4}{*}{ Age } & 10 & 10 & 23.8 & \\
\hline & 11 & 10 & 23.8 & \\
\hline & 12 & 11 & 26.2 & \\
\hline & 13 & 11 & 26.2 & \\
\hline \multirow{2}{*}{ Groups } & Exercise G. & 20 & 47.6 & \\
\hline & Control G. & 22 & 52.4 & \\
\hline
\end{tabular}

Table 2. Intergroup Comparison of Pretest Results

\begin{tabular}{ccccc}
\hline Parameters & Groups & $\mathbf{n}$ & $\mathbf{z}$ & $\boldsymbol{P}$ \\
\hline \multirow{2}{*}{ TFX } & EG. & 20 & -.462 & .596 \\
& CG. & 22 & & \\
TEX & EG. & 20 & -.527 & .621 \\
& CG. & 22 & & \\
TLF & EG. & 20 & -.534 & .527 \\
& CG. & 22 & & \\
BAH & EG. & 20 & -.602 & .574 \\
HGS left & CG. & 22 & & \\
HGS right & EG. & 20 & -.458 & .696 \\
& CG. & 22 & & \\
$* \mathrm{p}<0.05$ & EG. & 20 & -.582 & .672 \\
\hline
\end{tabular}


ICJRAS The Online Journal of Recreation and Sport -July 2021 Volume 10, Issue 3

Comparison of the initial measurements did not reveal any statistically significant result.

Table 3. Intergroup Comparison of Posttest Results

\begin{tabular}{ccccc}
\hline Parameters & Groups & $\mathbf{n}$ & $\mathbf{z}$ & $\boldsymbol{P}$ \\
\hline \multirow{2}{*}{ TFX } & EG. & 20 & -1.114 & .332 \\
& CG. & 22 & & \\
TEX & EG. & 20 & -.986 & .415 \\
& CG. & 22 & & \\
TLF & EG. & 20 & -1.130 & .212 \\
& CG. & 22 & & \\
BAH & EG. & 20 & -1.142 &. $\mathbf{. 0 1 0}$ \\
HGS left & CG. & 22 & & \\
& EG. & 20 & -1.123 & $\mathbf{. 0 0 6}$ \\
HGS right & CG. & 22 & & \\
& EG. & 20 & -1.342 & $\mathbf{. 0 1 8}$ \\
\hline
\end{tabular}

In the intergroup comparison of the posttest measurement results, no significant difference was found between the exercise and control groups in terms of their TFX, TEX and TLF values. On the other hand, the differences between the groups were significant on the level of $\mathrm{p}<0.05$ in terms of their BAH, HGS left and HGS right values.

Table 4. Intragroup Comparison of Pretest and Posttest Results

\begin{tabular}{c|c|c|c|c|c}
\hline Parameters & Groups & Measurements & $\mathbf{n}$ & $\mathbf{z}$ & $\boldsymbol{P}$ \\
\hline \multirow{2}{*}{ TFX } & EG. & Pre-Post & 20 & -1.212 & $\mathbf{. 0 0 3}$ \\
& CG. & Pre-Post & 22 & -1.120 & .074 \\
TEX & EG. & Pre-Post & 20 & -2.214 & $\mathbf{. 0 0 1}$ \\
& CG. & Pre-Post & 22 & -1.328 & .215 \\
TLF & EG. & Pre-Post & 20 & -2.115 &. $\mathbf{0 0 1}$ \\
& CG. & Pre-Post & 22 & -1.522 & .192 \\
BAH & EG. & Pre-Post & 20 & -2.112 &. $\mathbf{0 0 1}$ \\
& CG. & Pre-Post & 22 & -.252 & .059 \\
HGS left & EG. & Pre-Post & 20 & -2.220 &. $\mathbf{0 0 1}$ \\
& CG. & Pre-Post & 22 & -1.114 & .108 \\
HGS right & EG. & Pre-Post & 20 & -2.112 &. $\mathbf{0 0 1}$ \\
& CG. & Pre-Post & 22 & -1.251 & .192 \\
\hline
\end{tabular}

The intragroup comparisons between the pretest and posttest results of the groups revealed statistically significant differences in terms of the TFX, TEX, TLF, BAH, HGS left and HGS right values in the exercise group and no such significant difference in terms of these values in the control group.

\section{DISCUSSION}

In this study, it was observed that there were significant differences in the exercise group after the intervention regarding their flexibility, strength, arm strength and grip strength. 
The significant increase in flexibility in the exercise group coincided with the knowledge in the existing literature. Recent studies have reported that regular exercise has a positive impact on enhanced flexibility. Nelson et al. (2005) reported improvement in flexibility by stretching exercises [15]. Tekin et al. (2018) found similar results in a running exercise program for three months with female students suffering from obesity, where a significant improvement for arm strength was recorded [25]. Ranson et al. (2015) stated significant differences in 20-meter-long sit-up sprints, long-jumps with a pause and grip strength [17]. Their study showed that their participants significantly improved their grip strength. Most researchers have come up with similar results. The results of some researchers have varied, even if only to a small extent. Accordingly, these different results may be attributed to differences in the measurement instruments and methodologies for the analysis of grip strength in different studies [8, 22]. Significant improvements in grip strength as a part of similar studies based on sport climbing that involved sedentary young men and women were reported by Muehlbauer et al. (2012) and Aykora (2019) [14, 3]. It is clear according to the results of our study that the exercises increased muscle stamina, muscle strength and aerobic capacity. All previous data have been compatible with the results of our study.

\section{CONCLUSION}

The obtained results supported the hypothesis of this study. Regular core training exercises strengthen the flexibility and strength parameters. Due to its characteristics like training based on the person's own body weight, core training protects children physically and physiologically. Hence, students should be supported in doing such exercises while continuing their essential education. Similar studies could investigate different variables in different samples. Applying core training on elite athletes may contribute different and important data to this field of research. Therefore, future studies may be recommended to investigate changes which arise with core training, so that selection criteria for elite athletes could be determined easily. Core training could be more suitable for younger athletes for the reason that it only uses the person's own body weight, and so, it is recommended for children taking part in different sports branches.

\section{APPLICABLE REMARKS}

There were no conflicts of interest in this study. 


\section{REFERENCES}

[1] Amorim, T. P., Sousa, F. M. \& dos Santos, J. A. R. (2011). Influence of pilates training on muscular strength and flexibility in dancers. Motriz: Revista de Educação Física, 17(4), 660-666.

[2] Atan, T., Kabaday1, M., Elioz, M., Cilhoroz, B. T. \& Akyol, P. (2013). Effect of jogging and core training after supramaximal exercise on recovery. Turkish Journal of Sport and Exercise, 15(1), 73-77.

[3] Aykora, E. (2019). An Analysis over Physical and Physiological Parameters of Elementary School Children Taking Part in A Sport Climbing Exercise. Universal Journal of Educational Research $7(2), 624-628$.

[4] Bredin, S.S., Warburton, D. E. \& Lang, D.J. (2013). The health benefits and challenges of exercise training in persons living with schizophrenia: a pilot study. Brain Sciences, 3(2): 821-848.

[5] Casey, A. R., Kevin, R. F., Gregory, D. M. \& Timothy, E. H. (2012). "The effects of 1solated and integrated Core Stability' training on athletic performance measures” Sports Med. 42(8).

[6] Clark, M. A. (2001). Core stabilization training in rehabilitation. In: Techniques in Musculoskeletal Rehabilitation. Prentice, New York. 259-278.

[7] Dilber, A. O., Lağap, B., Akyüz, Ö., Çoban, C., Akyüz, M., Taş, M., Akyüz, F. \& Özkan, A. (2016). Erkek futbolcularda 8 haftalık kor antrenmanının performansla ilgili fiziksel uygunluk değişkenleri üzerine etkisi. CBÜ Beden Eğitimi ve Spor Bilimleri Dergisi, 11(2), 77-82.

[8] Grant, S., Hynes, V., Whittaker, A., Aitchison, T. (1996). Anthropometric, Strength and Flexibility Charecteristic of Elitand Recreational Climbers. J. Sports Sci., 14 (4), 301-304.

[9] Graves, J., Pollock, M. \& Foster, D. (1990). Effect of training frequency and specificity on isometric lumbar extension strength. Spine, 15:504-509.

[10] Hibbs, A. E., Thompson K. G., French D. N., Hodgson, D. \& Spears, I. E. (2011). Peak and Average Rectified EMG Measures: Which Method of Data Reduction Should be Used for Assessing core Training Exercises?, Journal of Electromyography and Kinesiology,21 102-111.

[11] Kloubec, J. A. (2010). Pilates for improvement of muscle endurance, flexibility, balance and posture. Journal of Strength and Conditioning Research, 24(3), 661-667.

[12] Lehman, G. J., Gordon, T., Langley, J., Pemrose, P. \& Tregaskis, S. (2005). Replacing a Swiss ball for an exercise bench causes variable changes in trunk muscle activity during upper limb strength exercises, Dynamic Medicine 4:6

[13] McGill, S. (2010). "Core Training: Evidence Translating to Better Performance and Injury Prevention" National Strength and Cond. 32v.n3. 33-46s

[14] Muehlbauer, T., Stuerchler, M. \& Granacher, U. (2012). Effects of Climbing on Core Strength and Mobility in Adults, Int J Sports Med, 33, 445-451 
[15] Nelson, A.G., Kokkonen, J. \& Arnall, D.A. (2005). Acute muscle stretching inhibits muscle strength endurance performance. Journal of Strength and Conditioning Research, 19 (2), 338-343.

[16] Otman, A. S., Demirel, H. \& Sade, A. (2003). Tedavi hareketlerinde temel değerlendirme prensipleri. 3. bask1. Ankara: Hacettepe Üniversitesi Fizik Tedavi ve Rehabilitasyon Yüksekokulu Yayınlart; p. 44-49.

[17] Ranson, R., Stratton, G. \& Taylor, S.R. (2015). Digit ratio (2D:4D) and physical fitness (Eurofit test battery) in school children, Early Human Development, 91 (5), 327-331.

[18] Rogers, K. \& Gibson, A. L. (2009). Eigth-week traditional mat pilates training-program effects on adult fitness characteristics. Research Quarterly for Exercise and Sport, 80(3), 569-574.

[19] Xibo S., Qian G., Honglei D. \& Shujie T. (2016). Which is Better in The Rehabilitation Of Stroke Patients, Core Stability Exercises or Conventional Exercises?, 28, 1131-1133.

[20] Samson, K. M., Sandrey, M. A. \& Hetrick, A. (2007). A core stabilization training program for tennis athletes. Athletic Therapy Today, 12(3), 41.

[21] Sekendiz, B., Çuğ, M. \& Korkusuz, F. (2010). Effects of Swiss-ball core strength training on strength, endurance, flexibility, and balance in sedentary women, J Strength Cond Res. Nov;24(11):3032-40.

[22] Su, C.Y., Lin, J.H., Chien, T.H., Cheng, K.F. \& Sung, Y.T. (1994). Grip Strength in Different Positions of Elbow and Shoulder. Archives of Physical Medicine and Rehabilitation 75 (7), 812815.

[23] Suni, J. H., Oja, P., Miilunpalo, S.I., Pasanen, M. E., Vuori, I.M. \& Bös, K. (1998). Healthrelated fitness test battery for adults: associations with perceived health, mobility, and back function and symptoms. Archives of Physical Medicine and Rehabilitation, 79(5), 559-569.

[24] Willardson, J. M. (2007). Core Stability Training for Healty Athletes: A Different Paradigm for Fitness Professionals. Strength Cond. J; 29: 42-49.

[25] Tekin, A., Tekin, G., Aykora, E., Çalışır, M. \& Duyan, M. (2018). Kor Stabilite Antrenmanının Kadın Çalışanların Vücut Kompozisyonu ve Kor Fonksiyona İlişkin Kuvvet ve Esneklik Parametrelerine Etkisi, İnönü Üniversitesi Beden Eğitimi ve Spor Bilimleri Dergisi, 5 (1), 41 -46.

[26] Bergmark, A. (1989). Stability of the lumbar spine. A study in mechanical engineering. Acta Orthop Scand 230: 1-54. 